\title{
Obesity and Cardiovascular Disease Risk Factors among the Indigenous and Immigrant Pakistani Population: A Systematic Review
}

\author{
Qaisar Raza $^{a}$ Colleen M. Doak ${ }^{a}$ Aroosa Khan $^{a}$ Mary Nicolaou $^{b}$ \\ Jaap C. Seidella

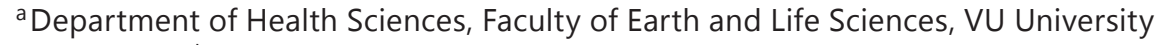 \\ Amsterdam, ${ }^{b}$ Department of Public Health, Academic Medical Centre, University of \\ Amsterdam, Amsterdam, The Netherlands
}

\author{
Key Words \\ Cardiovascular diseases - Obesity · Diabetes - Hypertension · Hypercholesterolemia · \\ Pakistanis
}

\begin{abstract}
Aim: The aim of this study was to systematically describe the gender and ethnic differences regarding the prevalence of general/central obesity and cardiovascular disease (CVD) risk factors such as diabetes mellitus type 2 , hypertension, and hypercholesterolemia among the indigenous and immigrant Pakistani communities. Methods: The search engine used was PubMed, supplemented with regional data from the Medical Institutes of Pakistan. The focus was on the adult Pakistani population (18 years and older). Results: We found only 7 studies among the immigrant Pakistani community and 24 studies among the indigenous Pakistani community. The studies had limitations such as low participation rates and use of self-reported data. There is a higher prevalence of central obesity among women (42.2\%) than among men (14.7\%) (National Health Survey of Pakistan). Certain ethnicities such as Muhajir and Baluchis showed a higher prevalence of cardiovascular risk factors when compared to other ethnicities in the indigenous Pakistani population. The results also indicate that the prevalence of obesity is $10-20 \%$ higher among the immigrant Pakistanis than in the indigenous Pakistanis. Conclusion: The relatively high prevalence of obesity and associated CVD risk factors (especially in women) among both indigenous and immigrant Pakistani populations require the attention of the healthcare professionals and policy makers, both inside and outside Pakistan.




\section{Introduction}

The epidemic of obesity is marked by alarming proportions globally [1]. It highly contributes to the burden of non-communicable diseases in general and cardiovascular disease (CVD) in particular [2,3]. The increasing trend of general and central obesity and associated morbidities (particularly glucose intolerance, diabetes mellitus type 2, dyslipidemia and hypertension) are also observed in South Asian populations [4, 5]. As a consequence, South Asians contribute to the highest proportion of the CVD burden globally [6].

Migration and acculturation are associated with an increase in obesity and in diet-related chronic diseases [7]. Several studies have documented an increase in obesity among the immigrant groups with longer stay in the Western countries [8-10]. In addition, there are studies from the UK which show an elevated risk of diabetes type 2 and coronary heart disease among immigrants from South Asia [11-13].

There are indications of differences in the prevalence of obesity and CVD-related risk factors among different South Asian ethnicities [14]. For example, Bhopal et al. [15] showed differences between Pakistanis, Indians and Bangladeshis regarding the prevalence of coronary heart disease risk factors in the UK; obesity was more prevalent in Pakistanis and Indians than in Bangladeshis. There are vast regional, ethnic, and religious divisions between the people of South Asia and the differences in disease risk and outcome may reflect this diversity. However, most of the studies which have reported on obesity and CVD have classified the South Asian population living in Western countries as one group [15].

Pakistan is one of those countries in South Asia, hosting a population of 170 million with large ethnic and linguistic divisions. Pakistan is administratively divided into four provinces, i.e. Punjab, Sindh, Baluchistan, and Khyber Pakhtunkhwa (KP), previously known as NorthWest Frontier Province (NWFP). The official estimates state that there are 100,000 deaths per year in Pakistan from CVDs which account for $12 \%$ of all-cause mortality [16]. A population-based study among persons 40 years and older found a prevalence of CVD of $26.9 \%$ in Karachi, Pakistan [17]. A study also showed that Pakistan ranks sixth globally regarding the number of persons with diabetes in a report entitled 'Capitalizing on the Demographic Transition: Tackling Non-Communicable Diseases in South Asia' submitted to the World Health Organization in 2011 [18].

\section{Aim of the Study}

Obesity along with diabetes mellitus type 2, hypertension, and hypercholesterolemia could be an important contributor to the high burden of CVDs among the Pakistanis (both indigenous and immigrant) (fig. 1). The increase in obesity and other CVD risk factors among the South Asian immigrants with an increasing length of stay in Western countries generates an interest to compare the prevalence of obesity-related CVD risk factors between the indigenous and the immigrant Pakistani community.

The aim of this systematic review is to answer the following research questions:

i) What are the gender and ethnic differences in terms of obesity-related CVD risk factors among the Pakistanis?

ii) What is the effect of migration on Pakistanis regarding obesity-related CVD risk factors? 
Raza et al.: Obesity and Cardiovascular Disease Risk Factors among the Indigenous and Immigrant Pakistani Population: A Systematic Review

Fig. 1. Potential risk factors leading to CVD in the Pakistani community.

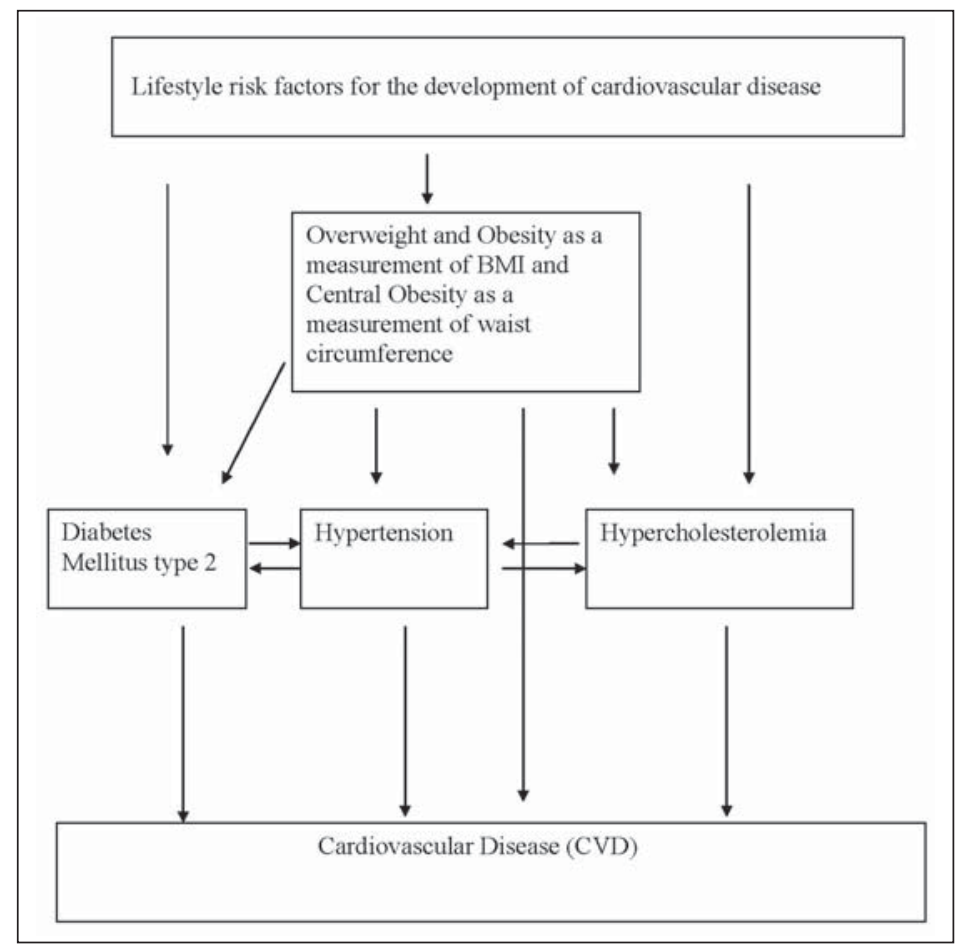

\section{Methods}

Inclusion Criteria

Studies were included if they met the following criteria:

i) The study focused on the Pakistani population or population of Pakistani origin.

ii) The study reported the prevalence of overweight, obesity, hypertension, diabetes mellitus type 2, insulin glucose tolerance, and hypercholesterolemia.

iii) The study did not report a prevalence but described mean values related to the above outcomes.

iv) The study focused on adults (18 years and older).

v) The literature search was restricted to the period of 1971-2011, the reason being that Pakistan consisted of two units named as East Pakistan and West Pakistan before 1971. After 1971, Pakistan was divided into two separate countries, i.e., East Pakistan became Bangladesh and West Pakistan became the current Pakistan. This review focuses on West Pakistan or the current Pakistan.

\section{Exclusion Criteria}

i) The studies related to East Pakistan (formerly part of Pakistan) were excluded.

ii) The studies focusing on individuals $<18$ years of age were excluded.

\section{Key Search Terms}

The key search terms used in the search were cardiovascular disease, CVD, Pakistan, overweight, obesity, BMI, diabetes mellitus type II, diabetes mellitus, NIDDM, hypertension, blood pressure, and cholesterol/lipids. Most of these keywords were used as Medical Subject Headings (MeSH). There were some headings such as Pakistan and CVD which were used as free-text terms.

\section{Search Strategy and Data Sources}

The database used was PubMed (www.Pubmed.com). Reference lists of relevant articles and reviews were used to trace the key publications. Furthermore, we contacted the Medical Institutes of Pakistan to extract the data published in the local journals. The literature search was also extended to the Urdu language on the presumption that there might be some literature in Urdu on CVDs among Pakistanis. For keywords and MeSH used for conducting the search please see http://content.karger.com/ProdukteDB/produkte. asp?doi=357176. 
Raza et al.: Obesity and Cardiovascular Disease Risk Factors among the Indigenous and Immigrant Pakistani Population: A Systematic Review

Procedure

Titles and abstracts were assessed by the first author (QR). The selected articles consisted only of original research with no abstracts, comments, or reviews. One of the other authors (MN) helped in assessing the titles and abstracts. In a second selection, full-text articles were assessed. Two other authors (CD and AK) helped in assessing the full-text articles. The authors assessed the selection procedure of the studies, and in the case of discordance the selection was discussed.

Quality of Studies

The quality of the studies was assessed on the basis of sample size, response rates, and the way of measurement (measured/self-report) (supplemental table 1 available at http://content.karger.com/ ProdukteDB/produkte.asp?doi=357176). The studies with a response rate of less than $33 \%$ and containing self-report were assessed as low-quality studies. This method has earlier been used by Ujcic-Voortman et al. [19] in a systematic review.

There is no precedence in the literature to qualify a study as 'low-quality' based on the sample size; there is no limit for maximum and minimum sample size. A general rule of thumb is that the more the better as long as there is no selection bias. Sample size is calculated to get an accurate and a precise account of the population. We are making an effort to provide a wide cut-off point for determining a 'low-quality study' in a review. Therefore, we arbitrarily decided that studies having a sample size less than 100 are 'low-quality studies'.

\section{Results}

The search in PubMed produced 1,489 articles. In addition, a recent conference report was received from Agha Khan Medical University which provided data on CVD and the associated risk factors among the South Asians as well as Pakistanis [18]. There was no literature available in the Urdu language on the prevalence of CVD risk factors. After assessing the abstracts and titles, 1,439 studies were excluded. Thus, 50 full-text articles were deemed suitable for inclusion. After assessing these full-text publications, 31 articles were finally included in the systematic review (fig. 2). There were 24 studies among the indigenous Pakistani population and 7 studies among the immigrant Pakistani population.

\section{Study Characteristics}

The studies included in this review varied greatly in terms of location, sample size, response rates, and reporting of gender differences. Most importantly, the definition for the CVD risk factors, namely diabetes mellitus, hypertension, overweight/obesity/central obesity, and hypercholesterolemia, varied in different studies.

Supplemental table 1 shows the study characteristics among the indigenous Pakistani population. Most of the studies were conducted in Karachi (a city in the Sindh province); the city with a population of approximately 18 million [20] encompassing a wide variety of ethnic, religious, and socioeconomic groups. In most of the studies, men had quite a low representation as compared to women.

Supplemental table 1 shows the study characteristics among the immigrant Pakistani population. We only found 7 studies among the immigrant Pakistanis, all of which were conducted in the UK and in Norway.

\section{Prevalence of CVD Risk Factors among the Indigenous Pakistani Population}

The studies among the indigenous Pakistani population were of varying quality. The national surveys (National Health Survey of Pakistan (NHSP) and Pakistan National Diabetes Survey (PNDS)) conducted in Pakistan had a large sample size and high response rates; in addition, the subjects were directly measured for their CVD risk factors (supplemental table 1). The national surveys are quite representative of the Pakistani population. Three 
Raza et al.: Obesity and Cardiovascular Disease Risk Factors among the Indigenous and Immigrant Pakistani Population: A Systematic Review

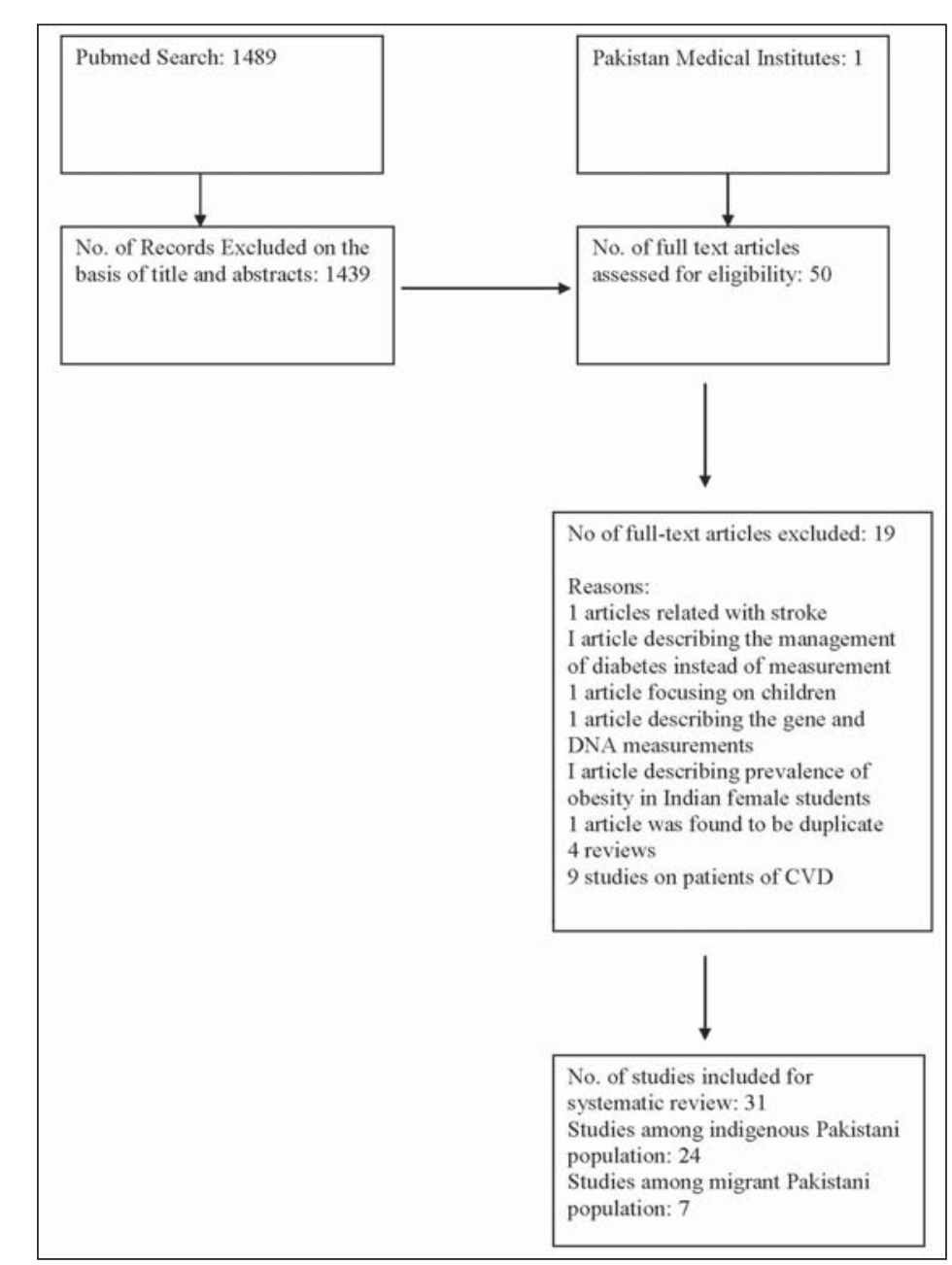
ing methods for the selection of articles.

studies were rated as 'low-quality' because of the use of self-report only (supplemental table 1).

Supplemental table 2 (available at http://content.karger.com/ProdukteDB/produkte. asp?doi=357176) shows the prevalence of obesity among the indigenous Pakistani population. In all studies, central obesity was defined as a waist circumference (WC) $>90 \mathrm{~cm}$ in men and a $\mathrm{WC}>80 \mathrm{~cm}$ in women. In studies that reported results stratified according to sex, the prevalence of central obesity was higher among women than among men: In the NHSP, central obesity was $42.2 \%$ among women compared to $14.7 \%$ among men (fig. 3 ).

Supplemental table 2 also shows that the levels of overweight and obesity as characterised by BMI varied in different studies due to differences in the cut-off points used. On this basis, gender differences were less consistent in terms of BMI.

Supplemental table 3 (available at http://content.karger.com/ProdukteDB/produkte. asp?doi=357176) shows the prevalence of diabetes mellitus type 2; the rates reported vary greatly and there are no clear gender differences observable. However, it is clear from this table that urban populations have a higher prevalence of diabetes than rural populations (PNDS) [21].

Similar to other outcomes, the prevalence of hypertension (supplemental table 4, available at http://content.karger.com/ProdukteDB/produkte.asp?doi=357176) varied in different studies, from as low as $4.1 \%$ (Muhajir men) to as high as $44.9 \%$ (women living in 


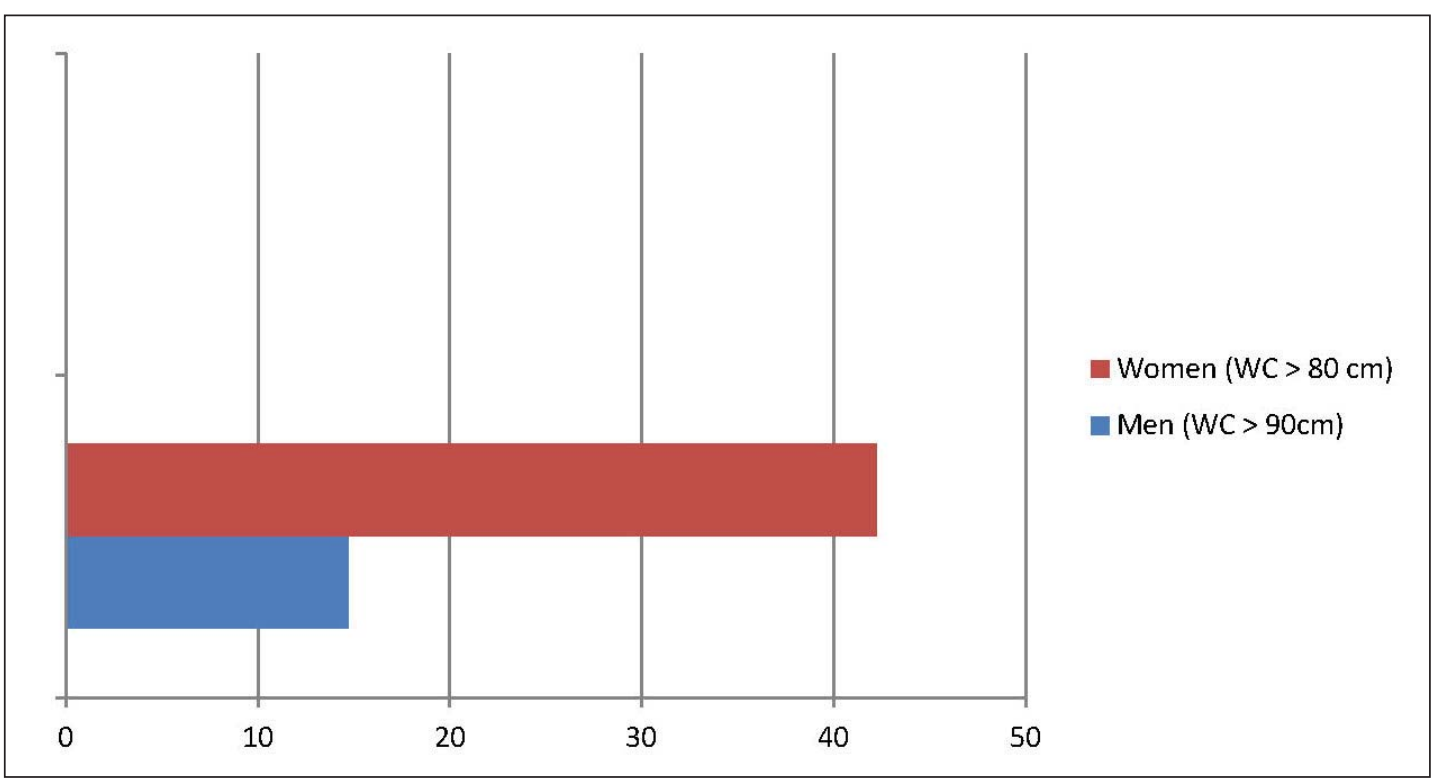

Fig. 3. Prevalence of central obesity as a measure of WC among men and women in the indigenous Pakistani population.

Karachi). There were no consistent gender differences regarding the prevalence of hypertension, although a higher prevalence among the women (44\%) than in men $21.8 \%)$ was reported by a study in Karachi; however, this outcome was based on self-reports [22].

Supplemental table 5 (available at http://content.karger.com/ProdukteDB/produkte. $a s p ? d o i=357176)$ reports wide variations in the prevalence of hypercholesterolemia and indicates a higher prevalence among women (14.6-38.1\%) than in men (10.1-31.3\%).

Furthermore, supplemental tables 2-4 show ethnic differences (NHSP). Women of Muhajir and Sindhi ethnicities had a higher mean WC than women of other ethnicities (fig. 4), while Muhajir men had a higher mean WC than men of other ethnicities. Muhajirs had a higher prevalence of diabetes than other ethnicities (fig. 5), which is in line with a higher mean WC among Muhajirs than other ethnicities. There were no clear gender differences between different ethnicities regarding the prevalence of diabetes. The Baluchi ethnicity showed a higher prevalence of hypertension than other ethnicities (fig. 6). Furthermore, supplemental table 3 shows that people living in the Sindh province had the highest prevalence of diabetes when compared to other provinces (PNDS). It is important to note that Sindhi and Muhajir ethnicities, which had the highest means for WC and a higher prevalence of diabetes in comparison with other ethnicities, mainly reside in the Sindh province.

Prevalence of CVD Risk Factors among the Immigrant Pakistani Population

The studies among the immigrant Pakistani population were also of varying quality. The nationally representative surveys of England as well as the Oslo Immigrant Health Studies had a large sample size. We found no studies among the immigrant Pakistanis that described ethnic differences within the Pakistani community.

Supplemental table 6 (available at http://content.karger.com/ProdukteDB/produkte. asp?doi=357176) shows the prevalence of CVD risk factors among the general immigrant Pakistani population. Generally, women had a higher prevalence of obesity, diabetes, and hypertension than men whereas men showed a higher prevalence of hypercholesterolemia 
Fig. 4. Mean WC of women among different ethnicities of the indigenous Pakistani population.

Fig. 5. Prevalence of diabetes among different ethnicities of the indigenous Pakistani population. (c) 2013 S. Karger $\mathrm{GmbH}$, Freiburg www.karger.com/ofa

Raza et al.: Obesity and Cardiovascular Disease Risk Factors among the Indigenous and Immigrant Pakistani Population: A Systematic Review
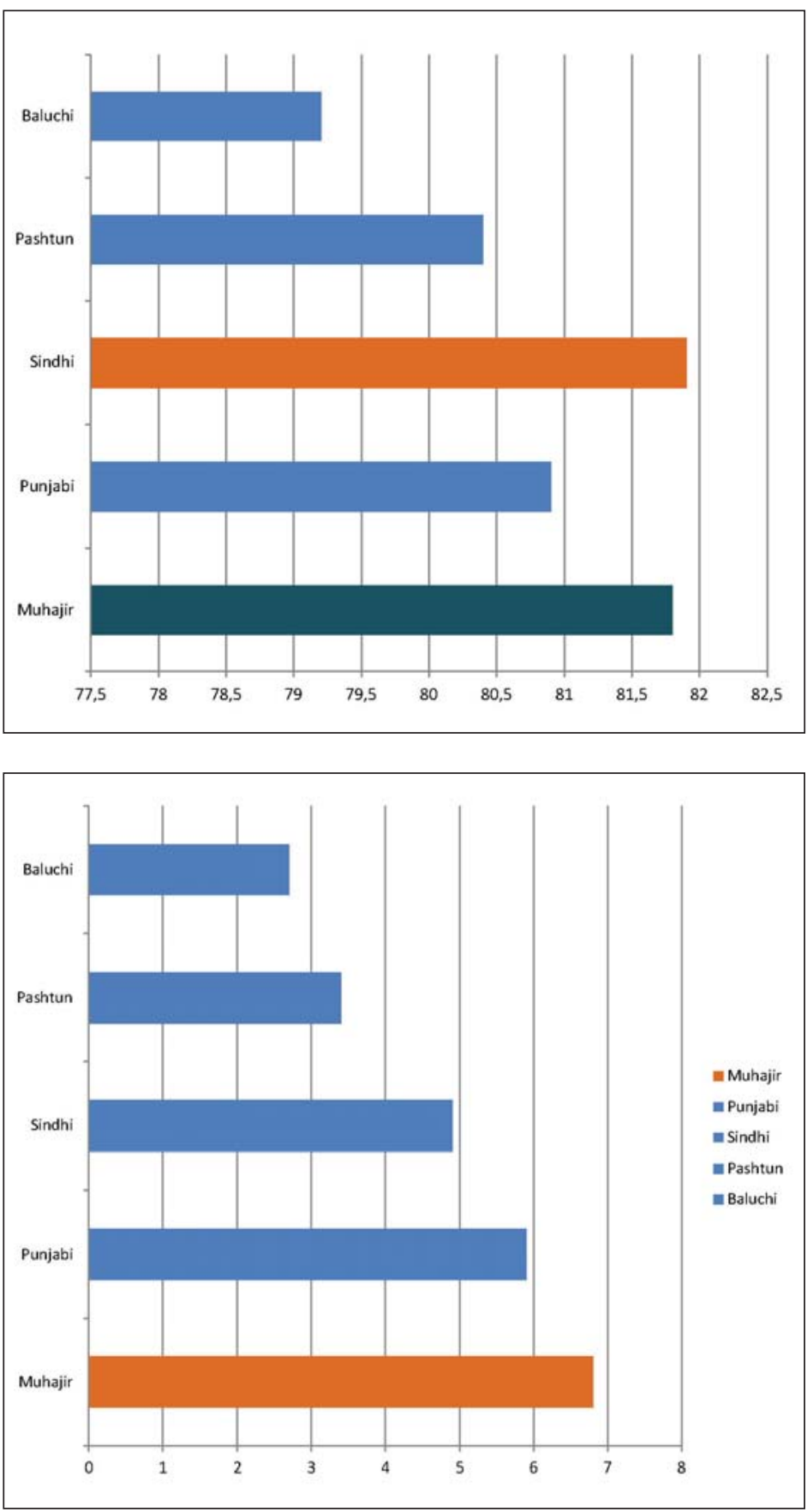

and low high-density lipoprotein cholesterol than women. One study by Zahid et al. [23] compared the prevalence of obesity of indigenous Pakistanis to the immigrant Pakistani population living in Oslo, Norway. The results of this study showed a higher prevalence of obesity among the immigrant Pakistanis than among those living in Pakistan (fig. 7). However, the indigenous Pakistani community was more hypertensive but had lower cholesterol levels than Pakistani immigrants living in Oslo. 
Raza et al.: Obesity and Cardiovascular Disease Risk Factors among the Indigenous and Immigrant Pakistani Population: A Systematic Review

Fig. 6. Prevalence of hypertension among different ethnicities of the indigenous Pakistani population.

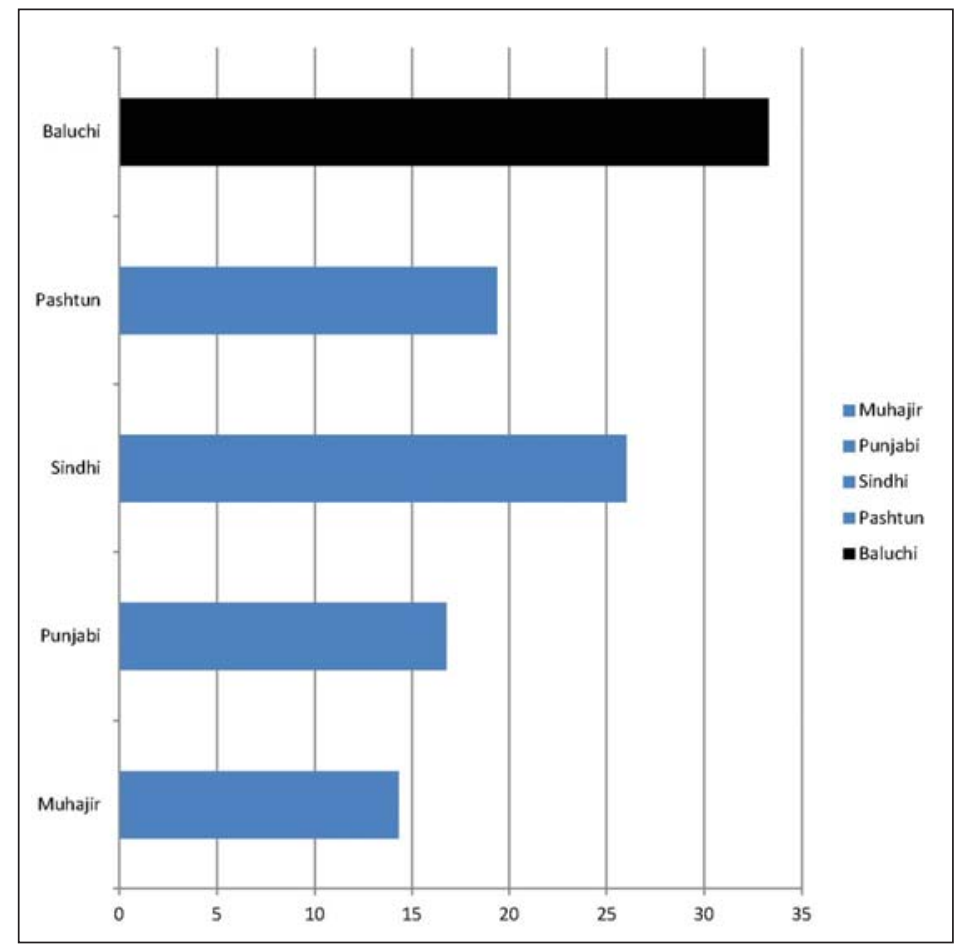

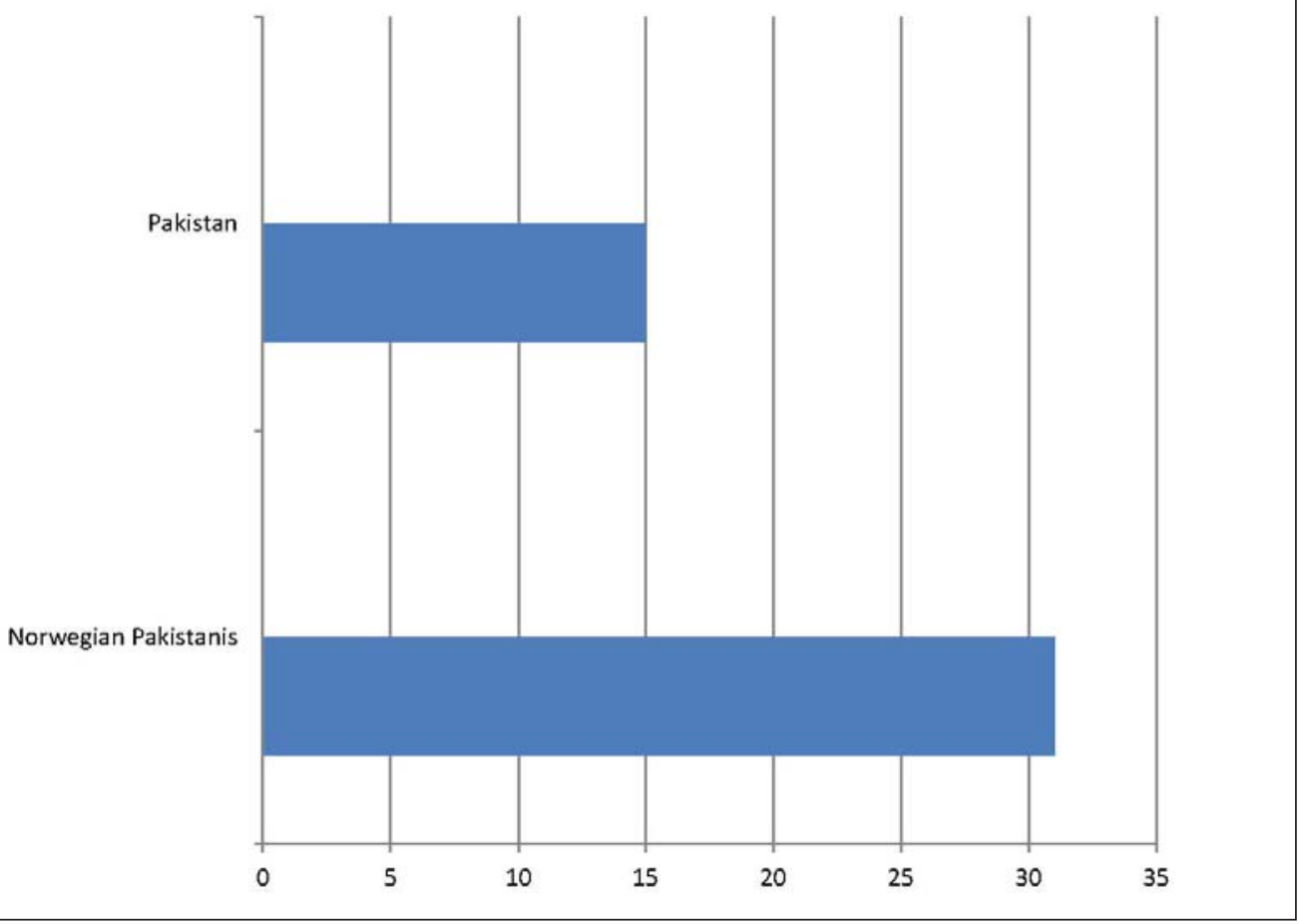

Fig. 7. Prevalence of obesity $\left(\mathrm{BMI}>30 \mathrm{~kg} / \mathrm{m}^{2}\right)$ among indigenous Pakistani and Norwegian Pakistani population. 
Raza et al.: Obesity and Cardiovascular Disease Risk Factors among the Indigenous and Immigrant Pakistani Population: A Systematic Review

\section{Discussion}

We found clear differences in the prevalence of obesity and cardiovascular risk factors in the Pakistani population according to sex, ethnicity, rural or urban residence, age, and immigrant status. The prevalence of overweight/obesity, diabetes mellitus type 2, hypertension, and cholesterol/lipids varied in different studies among Pakistani indigenous and immigrant groups due to the difference in their definition/cut-off points.

\section{Prevalence of CVD Risk Factors among the Indigenous Pakistani Community}

There were consistent results regarding the high prevalence of central obesity in different regions of Pakistan but we found inconsistent results regarding the prevalence of overweight and obesity based on BMI.

\section{Differences between Men and Women}

The NHSP (conducted in 1994 in Pakistan) shows that the prevalence of central obesity was particularly higher among the women than among the men [24]. There is also a higher prevalence of hypercholesterolemia among women than among men in the indigenous Pakistani population. The reasons for these differences are not clear, although gender differences regarding the dietary consumption patterns have been reported in some studies carried out among immigrant Pakistanis [25]. Nonetheless, there is a need for more studies to investigate gender differences in lifestyle among both the indigenous and immigrant Pakistani populations.

\section{Differences on the Basis of Ethnicity}

The NHSP also highlights some important ethnic differences. The Sindhi and Muhajir ethnicity show higher means of central obesity while the Baluchi ethnicity shows a higher prevalence of hypertension than other ethnicities. According to the NHSP, the Muhajir ethnicity also shows a higher prevalence of diabetes than other ethnicities.

These differences may be related to different lifestyles and socioeconomic status among the different ethnicities living in Pakistan. Both the Sindhi and Muhajir ethnic groups live predominantly in the Sindh province. Sindh has a highly diversified economy ranging from heavy industry and finance centred in and around Karachi to a substantial agricultural base along the Indus. Karachi, the capital of the Sindh province, is the economic hub, the largest city, and the main seaport and financial centre of Pakistan. According to the census of 1998, Muhajirs constitute almost 48\% of the total population of Karachi [26]. They are mostly involved in business and industry and generally belong to the higher socioeconomic class.

The Baluchi ethnicity lives in Baluchistan which is the least economically developed province of Pakistan. Baluchistan is situated in the southeast of Pakistan, constituting $44 \%$ of the country's total land mass and making it Pakistan's largest province by area but smallest in terms of population. The main source of income is the extraction of exhaustible natural resources, animal husbandry, and fish farming.

As a result, ethnic differences in CVD risk appear to reflect the differences in economic development and socioeconomic conditions. Untangling the contribution of socioeconomic factors to the ethnic differences regarding disease risk warrants more research.

The PNDS has also shown provincial differences in terms of diabetes prevalence; e.g., the province of Sindh shows a higher prevalence of diabetes than other provinces. These differences could be accounted for large linguistic, socioeconomic, and cultural differences among the four provinces of Pakistan. 
Raza et al.: Obesity and Cardiovascular Disease Risk Factors among the Indigenous and Immigrant Pakistani Population: A Systematic Review

\section{Rural and Urban Differences}

The PNDS was conducted from 1994 to 1998. The survey showed a higher prevalence of diabetes among the urban than among the rural population and is consistent with reports that CVD risk factors worsen with urbanisation [5]. This could be due to the change in lifestyle including diet after urbanisation. There is also credible evidence from the other populations in terms of differences in urban/rural and immigrant populations regarding the prevalence of overweight/obesity. For example, Agyemang et al. [27] showed a higher prevalence of obesity in Dutch-Ghanaians than in the indigenous Ghanaian population while the urban Ghanaians were more obese than the rural ones.

\section{Differences on the Basis of Age}

Differences in overweight and obesity described in the different studies reported here could be influenced by demographic differences in the age distribution of the populations studied. For example, due to a longer life expectancy, women are likely to be older than men, and this may explain the higher prevalence of obesity. Furthermore, immigrants of Pakistani origin may also have a higher life expectancy than their counterparts living in Pakistan, and this may also explain the differences found here. The studies on hypertension in this metaanalysis showed that older populations have a higher prevalence of hypertension than younger populations. A review article from Pakistan also reported that every third person in Pakistan above the age of 45 years suffers from hypertension [28].

\section{Prevalence of CVD Risk Factors among the Immigrant Pakistani Community}

The trend of a high prevalence of CVD risk factors also extends to the immigrant Pakistani population. Although there exists insufficient research into the immigrant Pakistani community, the few available studies have already shown the negative risk profile for immigrant Pakistanis in terms of prevalence of CVD risk factors. The national surveys conducted in Pakistan cannot be directly compared to the health surveys in England and the Oslo Immigrant Health Studies due to the different years the surveys were conducted in. However, Zahid et al. [23] showed that the prevalence of obesity was almost $10-20 \%$ higher in the immigrant Pakistani population living in Norway than in the indigenous Pakistani population. Thus, it seems that immigrant Pakistanis show a higher prevalence of obesity than indigenous Pakistanis. More comparative studies are needed between the indigenous and the immigrant Pakistanis in order to provide an insight into the effect of migration on the exposure to chronic disease risk factors among the immigrant Pakistanis.

Previous studies have shown that migration normally results in a worsening of the risk for CVD risk factors [7]. South Asians have shown a high prevalence of obesity and metabolic syndrome, as observed in a review [29]. Moreover, migration to Western countries might increase the risk for prevalence of obesity and CVD risk factors. An analysis of data from the UK indicates that Pakistani immigrants show a higher prevalence of CVD risk factors than other South Asian groups, namely immigrants from India [30]. Migration plays an important role in altering health due to the change in environmental and socioeconomic milieu, and ultimately lifestyle. For example, previous literature has reported a consumption of ghee among the immigrant South Asian community [31], which could provide an explanation for the higher prevalence of hypercholesterolemia and obesity among South Asian immigrants. A study from Oslo has also shown an increased consumption of oil and meat among the Pakistani immigrants living in Norway's capital [32].

\section{Quantity and Quality of Literature}

Most of the literature among the indigenous Pakistani population comes from Karachi, which could also be posed as a limitation due to the unavailability of data from other regions 
Raza et al.: Obesity and Cardiovascular Disease Risk Factors among the Indigenous and Immigrant Pakistani Population: A Systematic Review

of the country. Karachi is a big metropolis consisting of a diverse population with people coming from different backgrounds and ethnicities. However, this data is not sufficient enough to draw sound conclusions about the whole Pakistani population; thus, more studies in different regions of the country are needed.

There is a dearth of literature on immigrant South Asians, including the Pakistani population. Bhopal et al. [15] state that the heterogeneity of South Asian population is rarely acknowledged in terms of coronary heart disease'. There is a vital need for more studies among the Pakistani immigrant population, taking into consideration their ethnic subdivisions.

The studies conducted thus far pose some important limitations. Apart from the large surveys, there is often a problem of small sample size. Another limitation is the use of selfreported height and weight data, which can lead to an underestimation of obesity prevalence rates [33]. Finally, some studies do not mention the year the survey was carried out, which hampers drawing sound conclusions.

Future studies among the Pakistani population should have a strong focus on enhancing response rates; more data is especially needed for men. The data should be collected via objective methods, such as physical examinations. Differences in the design of the studies, such as sampling methods, the use of fasting versus non-fasting blood samples, or different cut-off points, may also have affected the results. Other data sources such as medical records of general practitioners and hospital discharge records may also add valuable knowledge on CVD (risk) among these groups.

This study has some limitations which need to be considered. We made every effort to include all major publications on CVD risk prevalence among the Pakistani community. Our results may have been influenced by publication bias, meaning that not all relevant studies may have been included.

\section{Conclusion}

The results of this study show that the Pakistani population frequently has risk factors for CVD, wherever they live. In particular, women appear to have a higher risk than men, and this gender difference is even more important in immigrant populations where the risk is highest. Public health interventions are needed to address these health concerns in women of Pakistani origin. Other differences within and between the Pakistani populations could be explained by socioeconomic factors related to lifestyle, in which case these risk factors are potentially modifiable through interventions. However, confirmation of these findings is necessary before specific intervention strategies are tried out. Formative research is needed to confirm that these results are not confounded by differences in population and that age structure is related to an increasing life expectancy.

\section{Acknowledgements}

\section{Funding}

The authors acknowledge the help for funding from the Higher Education Commission of Pakistan and the Free University, Amsterdam, The Netherlands. The funding sources had no involvement in the study design, data collection, data analysis, and interpretation of data. They also had no involvement whatsoever in the writing of the review and in the decision to submit the article for publication. 
Raza et al.: Obesity and Cardiovascular Disease Risk Factors among the Indigenous and Immigrant Pakistani Population: A Systematic Review

\section{Disclosure Statement}

The authors declare no conflict of interest.

\section{References}

Caballero B: The global epidemic of obesity: an overview. Epidemiol Rev 2007;29:1-5.

$>2$ Yusuf S, Hawken S, Ounpuu S, Dans T, Avezum A, Lanas F, Mcqueen M, Budaj A, Pais P, Varigos J, Lisheng L: Effect of potentially modifiable risk factors associated with myocardial infarction in 52 countries (the INTERHEART study): case-control study. Lancet 2004;364:937-952.

-3 Finucane MM, Stevens GA, Cowan MJ, Danaei G, Lin JK, Paciorek CJ, Singh GM, Gutierrez HR, Lu Y, Bahalim AN, Farzadfar F, Riley LM, Ezzati M; Global Burden of Metabolic Risk Factors of Chronic Diseases Collaborating Group (Body Mass Index): National, regional, and global trends in body-mass index since 1980: systematic analysis of health examination surveys and epidemiological studies with 960 country-years and 9.1 million participants. Lancet 2011;377:557-567.

4 McKeigue PM, Shah B, Marmot, MG: Relation of central obesity and insulin resistance with high diabetes prevalence and cardiovascular risk in South Asians. Lancet 1991;337:382-386.

5 Reddy KS, Yusuf S: Emerging epidemic of cardiovascular disease in developing countries. Circulation 1998; 197:596-601.

6 Ramaraj R, Chellappa P: Cardiovascular risk in South Asians. Postgrad Med 2008;84:518-523.

7 Neuhouser ML, Thompson B, Gloria D, Coronado GD, Solomon CC: Higher fat intake and lower fruit and vegetables intakes are associated with greater acculturation among Mexicans living in Washington State. J Am Diet Assoc 2004; 104:51-57.

8 Cairney J, Ostbye T: Time since immigration and excess body weight. Can J Public Health 1999;90:120-124.

$\checkmark 9$ Lauderdale DS, Rathoug PJ: Body mass index in a US national sample of Asian Americans: effects of nativity, years since immigration and socioeconomic status. Int J Obes Relat Metab Disord 2002;24:1188-1194.

10 Goel MS, Carthy EP, Phillips RS, Wee CC: Obesity among US immigrant subgroups by duration of residence. JAMA 2004;292:2860-2867.

11 Mather HM, Keen H: The Southall Diabetes Survey: prevalence of known diabetes in Asians and Europeans. Br Med J (Clin Res Ed) 1985;291:1081-1084.

$\checkmark 12$ McKeigue PM, Miller GJ, Marmot MG: Coronary heart disease in South Asians overseas: a review. J Clin Epidemiol 1989;42:597-609.

13 Davey SG, Chaturvedi N, Harding S, Nazroo J, Williams R: Ethnic inequalities in health: a review of UK epidemiological evidence. Crit Pub Health 2000;10:2000.

14 Bhopal RS: Heterogeneity among Indians, Pakistanis, and Bangladeshis is key to racial inequities. BMJ 2002; 325:903.

15 Bhopal RS, Unwin N, White M, Yallop J, Walker L, Alberti KG, Harland J, Patel S, Ahmad N, Turner C, Watson B, Kaur D, Kulkarni A, Laker M, Tavridou A: Heterogeneity of coronary heart disease risk factors in Indian, Pakistani, Bangladeshi, and European origin populations: cross sectional study. BMJ 1999;319:215-220.

16 Ahmad K: Facing up to Pakistan's cardiovascular challenge. Lancet 2002;359:859.

-17 Jafar TH, Jafary FH, Jessani S, Chaturvedi N: Heart disease epidemic in Pakistan: women and men at equal risk. Am Heart J 2005;150:221-226.

18 Engelgau M, El-Saharty S, Kudesia P, Rajan V, Rosenhouse S, Okamoto K: Capitalizing on the Demographic Transition: Tackling Noncommunicable Diseases in South Asia. Washington DC, The World Bank, 2011, p 204.

19 Ujcic-Voortman JK, Baan CA, Seidell JC, Verhoeff AP: Obesity and cardiovascular disease risk among Turkish and Moroccan migrant groups in Europe: a systematic review. Obes Rev 2011;13:2-16.

20 The largest cities in the world and their mayors, 2012. www.citymayors.com/statistics/largest-cities-mayors-1. html. (Accessed 07.11.2012)

-21 Shera AS, Jawad F, Maqsood A: Prevalence of diabetes in Pakistan. Diabetes Res Clin Pract 2007;76:219-222.

-22 Ladha A, Khan RS, Malik AA, Khan SF, Khan B, Khan IN, Samiullah, Kayani WT, Saleem S: The health seeking behaviour of elderly population in a poor-urban community of Karachi, Pakistan. J Pak Med Assoc 2009;59: 89-92.

-23 Zahid N, Meyer HE, Kumar BN, Claussen B, Hussain A: High levels of cardiovascular risk factors among Pakistanis in Norway compared to Pakistanis in Pakistan. J Obes 2011;2011:163749.

-24 Jafar TH, Levey AS, White FM, Gul A, Jessani S, Khan AQ, Jafary FH, Schmid CH, Chaturvedi N: Ethnic differences and determinants of diabetes and central obesity among South Asians of Pakistan. Diabet Med 2004;21:716-723.

25 Jamal A: Food consumption among ethnic minorities: the case of British-Pakistanis in Bradford, UK. Brit Food J 1998;100:221-227.

26 Population Census Organization of the Government of Pakistan 1998. www.census.gov.pk/ (Accessed 7.11.2012).

-27 Agyemang C, Owusu-Dabo E, De Jonge A, Martins D, Ogedegbe G, Stronks K: Overweight and obesity among Ghanaian residents in The Netherlands: how do they weigh against their urban and rural counterparts in Ghana? Public Health Nutr 2009;12:909-916. 
Raza et al.: Obesity and Cardiovascular Disease Risk Factors among the Indigenous and Immigrant Pakistani Population: A Systematic Review

Wandel M, Raberg M, Kumar B, Holmboe-Ottesen G: Changes in food habits after migration among South Asians settled in Oslo: the effect of demographic, socio-economic and integration factors. Appetite 2008;50: 376-385.

-33 Visscher TL, Viet AL, Kroesbergen IHT, Seidell JC: Underreporting of BMI in adults and its effect on obesity prevalence estimations in the period 1998 to 2001. Obesity (Silver Spring) 2006;14:2054-2063.

-34 Shera AS, Basit A, Fawwad A, Hakeem R, Ahmedani MY, Hydrie MZ, Khwaja IA: Pakistan National Diabetes Survey: prevalence of glucose intolerance and associated factors in the Punjab Province of Pakistan. Prim Care Diabetes 2010;4:79-83.

-35 Shera AS, Rafique G, Khawaja IA, Baqai S, King H: Pakistan National Diabetes Survey: prevalence of glucose intolerance and associated factors in Baluchistan province. Diabetes Res Clin Pract 1999;44:49-58.

-36 Shera AS, Rafique G, Ahmed KI, Baqai S, Khan IA, King H: Pakistan National Diabetes Survey: prevalence of glucose intolerance and associated factors in North West Frontier Province (NWFP) of Pakistan. J Pak Med Assoc 1999;42:206.

-37 Shera AS, Rafique G, Khawaja IA, Ara J, Baqai S, King H: Pakistan National Diabetes Survey: prevalence of glucose intolerance and associated factors in Shikarpur, Sindh Province. Diabet Med 1995;12:1116-1121.

-38 Jafar TH, Chaturvedi N, Pappas G: Prevalence of overweight and obesity and their association with hypertension and diabetes mellitus in an Indo-Asian population. CMAJ 2006;175:1071-1077.

39 Jafar TH, Levey AS, Jafary FH, White F, Gul A, Rahbar MH, Khan AQ, Hattersley A, Schmid CH, Chaturvedi N: Ethnic subgroup differences in hypertension in Pakistan. J Hypertens 2003;21:905-912.

40 Nanan D: The obesity pandemic - implications for Pakistan. J Pak Med Assoc 2002;52:342-346.

41 Mahar PS, Awan MZ, Manzar N, Memon MS: Prevalence of type-II diabetes mellitus and diabetic retinopathy: the Gaddap study. J Coll Physicians Surg Pak 2010;20:528-532.

-42 Hingorjo MR, Syed S, Qureshi MA: Overweight and obesity in students of a Dental College of Karachi: lifestyle influence and measurement by an appropriate anthropometric index. J Pak Med Assoc 2009;59:528-532.

-43 Nisar N, Qadri MH, Fatima K, Perveen S: Dietary habits and life style among the students of a private medical university Karachi. J Pak Med Assoc 2008;58:687-690.

-44 Jafar TH, Qadri Z, Chaturvedi N: Coronary artery disease epidemic in Pakistan: more electrocardiographic evidence of ischaemia in women than in men. Heart 2008;94:408-413.

-45 Aziz K, Aziz S, Patel N, Faruqui AMA, Chagani H: Coronary heart disease risk-factor profile in a lower middles class urban community in Pakistan. East Mediterr Health J 2005;11:258-272.

$\checkmark 46$ Siddiqui H, Anjum Q, Omair A, Usman J, Rizvi R, Ashfaq T: Risk factors assessment for hypertension in a squatter settlement of Karachi. J Pak Med Assoc 2005;55:390-392.

-47 Safdar S, Omair A, Faisal U, Hasan H: Prevalence of hypertension in a low income settlement of Karachi. J Pak Med Assoc 2004;54:506-509.

48 Shah SM, Nanan D, Rahbar MH, Rahim M, Nowshad G: Assessing obesity and overweight in a high mountain Pakistani population. Trop Med Int Health 2004;9:526-532.

-49 Basit A, Hydrie MZI, Hakeem R, Ahmed K: Prevalence of diabetes, impaired fasting glucose and associated risk factors in a rural area of Baluchistan province according to new ADA Criteria. J Pak Med Assoc 2002;52:357360.

50 Shah SMA, Luby S, Rahbar M, Khan AW, McCormick JB: Hypertension and its determinants among adults in high mountain villages of the Northern Areas of Pakistan. J Hum Hypertens 2001;15:107-112.

-51 Dodani S, Mistry R, Khwaja A, Farooqi M, Qureshi R, Kazmi K: Prevalence and awareness of risk factors and behaviours of coronary heart disease in an urban population of Karachi, the largest city of Pakistan: a community survey. J Public Health (Oxf) 2004;26:245-249.

52 Iqbal SP, Dodani S, Qureshi R: Risk factors and behaviours for coronary artery disease (CAD) among ambulatory Pakistanis. J Pak Med Assoc 2004;54:261-266.

53 Akatsu H, Aslam A: Prevalence of hypertension and obesity among women over age 25 in a low income area in Karachi, Pakistan. J Pak Med Assoc 1996;46:191-193.

54 Kumar BN, Meyer HE, Wandel M, Dalen I, Holmboe-Ottesen G: Ethnic differences in obesity among immigrants from developing countries, in Oslo, Norway. Int J Obes 2006;30:684-690.

55 Glenday K, Kumar BN, Tverdal A, Meyer HE: Cardiovascular disease risk factors among five major ethnic groups in Oslo, Norway: the Oslo Immigrant Health Study. Eur J Cardiovasc Prev Rehabil 2006;13:348-355.

$\checkmark 56$ Tran T, Straand J, Diep LM, Meyer HE, Birkeland KI, Jenum AK: Cardiovascular disease by diabetes status in five ethnic minority groups compared to ethnic Norwegians. BMC Public Health 2011;11:554.

57 Riste L, Khan F, Cruickshank K: High prevalence of type 2 diabetes in all ethnic groups, including Europeans, in a British inner city: relative poverty, history, inactivity, or 21st century Europe? Diabetes Care 2001;24: 1377-1383. 